\title{
PERANGKAT LUNAK PENCATATAN PAJAK PADA BAGIAN AKUNTANSI (STUDI KASUS : PT STILUS UTAMA MATERIALS BANDUNG)
}

\author{
Heri Purwanto $^{1}$, Mochamad Cory Sakti Triwangsa ${ }^{2}$, Chika Gustiana Widiarestuwati ${ }^{3}$, \\ Prodi Teknik Informatika, STMIK LPKIA Bandung ${ }^{1,2}$ \\ Prodi Manajemen Informatika, Politeknik Komputer Niaga LPKIA ${ }^{3}$ \\ Jl. Soekarno-Hatta No.456, Batununggal, Kec. Bandung Kidul, Kota Bandung, Jawa Barat 40266 $6^{1,2,3}$ \\ heripurwanto@lpkia.ac.id ${ }^{1}$, $180914039 @$ fellow.lpkia.ac.id ${ }^{2}$, $180623002 @$ fellow.lpkia.ac.id ${ }^{3}$
}

\begin{abstract}
Abstrak
Penelitian ini bertujuan untuk merancang perangkat lunak yang akan digunakan pada bagian akuntansi dengan fungsi untuk mendata transaksi klien sesuai proses bisnis berjalan yang telah ada dengan tujuan dapat memberikan informasi tentang piutang client secara tepat dan akurat serta dapat menghindari penumpukan dokumen-dokumen piutang client, meminimalisir kehilangan data client, metode penelitian menggunakan metode kualitatif dan data yang diperlukan untuk merancang perangkat lunak didapat dari hasil wawancara dan observasi, pendekatan yang digunakan untuk mendapatkan hasil yaitu dengan mengembangkan aplikasi yang digunakan dalam penelitian ini menggunakan metode prototype yang menghasilkan perangkat lunak berbasis web menggunakan framework laravel dengan hasil penelitian disajikan dalam bentuk prototype berupa aplikasi web menggunakan framework laravel disertakan dengan pedoman pembuatan aplikasi seperti Usecase, diagram aktivitas, diagram kelas, perancangan database, mockup user interface, serta hasil jadi aplikasi. Aplikasi telah diuji cobakan pada komputer dengan spesifikasi yang telah ditentukan dan telah dilakukan pengujian black box yang pengujian dilakukan beberapa fungsi yang telah ditentukan sebelumnya hasil dari pengujian black box. menunjukkan bahwa aplikasi berjalan seperti yang dirancang dan dapat menggantikan proses bisnis berjalan perusahaan PT. Stilus Utama Materials Bandung serta dapat meminimalisir kehilangan data client sesuai dengan tujuan penelitian. untuk penelitian selanjutnya program akan dibuat dalam platform lain seperti node $j s$ atau mobile dan bisa dilakukan perbandingan performance dengan laravel pada platform node js atau dalam versi mobile.
\end{abstract}

Kata kunci :

Perancangan Perangkat Lunak, Framework Laravel, Proses Bisnis Berjalan

\begin{abstract}
This study aims to design software that will be used in the accounting department with a function to record client transactions according to existing business processes with the aim of being able to provide information about client receivables precisely and accurately and can avoid the accumulation of client receivable documents, minimizing loss client data, research methods use qualitative methods and the data needed to design software are obtained from interviews and observations, the approach used to obtain results is to develop applications used in this study using a prototype method that produces webbased software using the laravel framework with research results presented in the form of a prototype in the form of a web application using the laravel framework included with application development guidelines such as use cases, activity diagrams, class diagrams, database design, user int mockups interface, as well as the finished application. The application has been tested on a computer with predetermined specifications and black box testing has been carried out in which several functions have been determined previously as a result of black box testing. shows that the application runs as designed and can replace the current business processes of PT. Stylus Utama Materials Bandung and can minimize the loss of client data in accordance with the research objectives. for further research, the program will be made on other platforms such as node js or mobile and performance comparisons can be made with
\end{abstract}

Heri Purwanto, Mochamad Cory Sakti Triwangsa, Chika Gustiana Widiarestuwati 
laravel on the node js platform or in the mobile version.

Keywords :

Software Design, Laravel Framework, Running Business Process.

\section{Pendahuluan}

Pajak yaitu upaya yang digunakan oleh negara dalam rangka menambahkan penerimaan negara secara mandiri (Hardiningsih, 2011). Pajak merupakan tagihan wajib yang asalnya dari subjek pajak dan dialamatkan kepada pemerintah (Fitriani \& Sulistyawati, 2020). Pencatatan merupakan proses atau pembuatan, cara mencatat atau menuliskan sesuatu ke buku dan komputer(Prasetyo, 2020). Akuntansi merupakan parameter utama kinerja usaha yang harus dicapai (Ediraras, 2010). Akuntansi dapat diartikan sebagai sistem informasi yang merealisasi laporan kepada orang orang yang berkaitan dengan kegiatan ekonomi dan keadaan perusahaan (Mulyani, Nurhayaty, \& Miharja, 2019). Perangkat lunak merupakan peralatan tidak berwujud yang membutuhkan pengetahuan spesifik tentang pembuatan perangkat lunak yang baik dan efisien dengan strategi teknik(Primawati \& Mustari, 2014). Ketidak hadirannya perangkat lunak, akan menyebabkan perangkat keras yang telah dirancang, tidak akan berjalan dengan semestinya (Maulana, 2017).

PT. STILUS UTAMA MATERIALS adalah perusahaan yang bergerak dibidang jasa manajemen dan pajak. Disana mereka melayani banyak karyawan yang mengalami kesulitan dalam pajak. Berbagai kalangan datang kesini untuk mengurusi pajak mereka. Namun, pencatatan klien PT. STILUS UTAMA MATERIALS masih menggunakan alat tulis dan kertas, di jaman modern, Tidak bisa dihindari, kemajuan teknologi informasi yang cepat dalam kurun waktu singkat ini menyebabkan berbagai dorongan perubahan dalam kehidupan bermasyarakat (Khairiyah \& Akhmadi, 2018). Perubahan ini dapat dilihat dari perubahan pencatatan data melalui tulisan menjadi melalui komputer.

Penelitian perangkat lunak pencatatan pajak ini sebelumnya telah diuji oleh peneliti lain dengan studi kasus yang berbeda - beda, seperti penelitian Aplikasi pencatatan transaksi UMKM berbasis website dan bantuan CodeIgniter (Wibisono, Surya, Putra, \&
Margita, 2020), penelitian tentang membuat sistem pencatatan sesuai dengan kebutuhan perusahaan sehingga perusahaan dapat mengetahui kondisi perusahaan sebenarnya(Tegar, 2014) namun terdapat perbedaan pada studi kasus yang berbeda yaitu di PT Stilus Utama Materials dan menggunakan framework laravel. Penelitian ini bertujuan untuk merancang perangkat lunak jasa konsultan pajak pada bagian akuntansi di PT STILUS UTAMA MATERIALS BANDUNG. Oleh karena itu pada penelitian ini memiliki tujuan untuk mengembangkan sebuah sistem informasi akuntansi pajak berbasis website yang dibuat berdasarkan penelitian yang sudah ada namun dibuat dalam framework laravel dan diimplementasikan pada perusahaan.

Untuk metodologi yang digunakan menggunakan metode kualitatif dengan data dikumpulkan menggunakan metode observasi dan metode wawancara dan metode pengembangan yang dipakai untuk pembangunan sistem informasi ini yaitu metode prototype dan dimodelkan menggunakan UML.

\section{KAJIAN LITERATUR}

Pada bab ini, akan dijelaskan pengertian dan konsep yang berhubungan dengan penelitian berdasarkan kajian literatur

\section{II.1 Pajak}

Pajak merupakan pungutan kepada pemerintah bersifat mengikat, yang memiliki kewajiban wajib membayarnya sesuai ketentuan hukum, dengan tidak adanya ganjaran kembali secara langsung dan yang digunakan sebagai alat untuk membayar pembiayaan umum yang berkaitan berkaitan dengan misi pemerintah berdasarkan aturan pemerintahan (Mandak \& Morasa, 2015).

\section{II.2 Website}

Website merupakan bentuk aplikasi yang mengandung manuskrip berbagai sarana seperti teks, gambar, suara, animasi, dan video yang dibungkus memakai bantuan protokol hyper text transfer protocol(HTTP) dan jika ingin membukanya diperlukan perangkat lunak yang disebut browser (Suhartanto, 2016). Browser dapat diartikan perangkat lunak yang mampu mengelola manuskrip website dengan cara diartikan ke bahasa mesin. Semau proses dilakukan oleh web engine. Semua manuskrip website

Heri Purwanto, Mochamad Cory Sakti Triwangsa, Chika Gustiana Widiarestuwati 
ditunjukkan dengan cara diterjemahkan (Mumtahana, Nita, \& Tito, 2017).

\section{II.3 Perangkat Lunak}

Perangkat lunak dapat diartikan sebagai generalisasi materi yang mengizinkan pengguna untuk terhubung dengan perangkat keras. Ketidakhadiran aplikasi berdampak pada perangkat keras yang telah dirancang tidak dapat melakukan fungsinya dengan baik(Maulana, 2017).

\section{II.4 Basis Data}

Basis data merupakan kawanan data dan penjelasannya yang terhubung secara logika berfungsi untuk mendapatkan informasi. Data secara wujud direkam dalam bentuk himpunan bit yang terekam dengan asas track pada gawai penyimpanan. Secara prakteknya data disusun dengan format secara logis sehingga kumpulan tabel menyusun basis data, sedangkan tabel terangkai atas sebanyak record, dan record berisi sejumlah field, lalu field disimpan dalam himpunan bit (Dalimunthe, 2016).

\section{II.5 Diagram Use Case}

Use case diagram diperlukan untuk menggambarkan apa yang seharusnya digarap oleh sistem. Diagram use case mengadakan cara menggambarkan pandangan eksternal terhadap sistem dan hubungannya terhadap luar sistem(Handayani, 2018).

\section{II.6 Diagram aktivitas}

Diagram aktivitas merupakan bentuk pengembangan dari state chart yang berfokus pada kegiatan-kegiatan, bagian-bagian dari proses yang berelasi dengan kiat-kiat anggota maupun aktivitas aktivitas yang terjadi (Mumtahana et al., 2017).

\section{II.7 Class Diagram}

Diagram Kelas merupakan ikatan antar kelas kelas dan elaborasi terhadap detail tiap-tiap kelas yang ada di dalam desain model dari suatu sistem, kelas diagram juga memperlihatkan kaidah-kaidah dan tugas utama entitas yang menentukan perilaku sistem (Urva, Siregar, Prof, Kisaran, \& Utara, 2015).

\section{II.8 Hypertext Preprocessor(PHP)}

PHP merupakan skrip yang terhubung dengan HyperText Markup Language (HTML) dan berada bagian peladen(Fridayanthie, Wida \& Mahdiati, 2016). PHP diartikan sebagai skrip yang dipakai untuk merancang halaman web dinamis, dinamis berarti halaman yang nantinya ditampilkan diciptakan saat halaman itu diminta oleh klien terbaru (Ariesandika, Wicaksono, \& Pradana, 2018).

\section{II.9 Laravel}

Laravel merupakan bentuk Model View Controller $(M V C)$ web development framework yang dibangun untuk menaikkan kadar aplikasi dengan mencoba memotong biaya pemekaran dan pembaharuan serta menaikkan kecepatan pembuatan operasi dengan sintak yang tersusun rapi dan efektif yang dapat memangkas banyak waktu yang diperlukan untuk implementasi(Lutfi, 2017).

\section{II.10 Black Box Texting}

Black-box yang dikenal sebagai uji fungsional, merupakan keadaan uji yang dibangun berdasarkan program atau tugas sistem yaitu tester, tester memanfaatkan data input dan output yang kemudian dianalisis, tetapi tester tidak perlu tahu bagaimana sistem atau program berjalan. tester berpusat pada pemeriksaan fungsi perangkat lunak terhadap spesifikasi yang telah ditetapkan. dengan pengujian cara black-box, tester memperhatikan program sebagai kubus hitam dan tidak memikirkan struktur internal dari perangkat lunak atau sistem (E. Lewis, 2016).

\section{AnAlisis dan Perancangan}

Pada bab ini, akan dijelaskan pengertian dan konsep yang berhubungan dengan penelitian berdasarkan kajian literatur

\section{III.1 Profil Perusahaan}

Berdasarkan hasil wawancara didapat fakta bahwa, PT. STILUS UTAMA MATERIALS yaitu perusahaan konsultan pajak yang bergerak dibidang jasa konsultan perpajakan, Software, dan Management yang didirikan oleh Ifan Kurniawan.

Perusahaan yang telah menjadi klien konsultan pajak memiliki usaha yang beraneka ragam, seperti: restoran, garmen, perdagangan, industri kecil, industry besar.

Hingga saat ini tercatat sebanyak 50 perusahaan yang berstatus klien PT. STILUS UTAMA MATERIALS. Mayoritas dari klien-klien tersebut merintis di bagian pabrik garmen, kemudian diikuti oleh perumahan, dan konstruksi. 
PT. STILUS UTAMA MATERIALS sebagai perusahaan yang bergerak dibidang jasa konsultan berorientasi profit memiliki tujuan yaitu mampu bersaing dan meningkatkan keuntungan. Untuk mewujudkan tujuan yang telah ditetapkan, konsultan pajak perlu menjabarkan visi dan misi yang akan dijalankan. Karena hal tersebut berperan penting sebagai pemandu tindakan pimpinan di masa depan. Rumusan visi dan misi memuat pertanyaan tentang filsafat bisnis yang dianut oleh manajemen puncak, dapat juga memberikan gambaran tentang image yang ingin dikenali oleh berbagai kelompok berkepentingan, mencerminkan pandangan organisasi tentang dirinya sendiri, bidang usaha yang ditekuni dan produk yang dihasilkan.

\section{III.2 Proses Bisnis Berjalan}

Proses bisnis berjalan pada PT. Stilus Utama Materials ini dideskripsikan dalam beberapa tahap, dalam hal ini Konsultan Pajak yang menerima client dan ingin ditangani masalah perpajakan perusahaannya, para client diminta langsung datang ke kantor atau bisa melalui nomor telepon pimpinan untuk membicarakan masalah apa yang ingin ditanyakan oleh client, apabila client tersebut setuju dan berminat maka akan diberikan formulir pendaftaran client baru. Setelah diberikan formulir pendaftaran, maka client bisa datang ke kantor dan membawa formulir pendaftaran client terebut ke bagian akuntansi agar data dari formulir tersebut bisa langsung diproses datanya dan apabila data tersebut valid akan diarsipkan ke data client dan akan langsung dilakukan pemberitahuan terhadap client tersebut. Kemudian bagian akuntansi menyiapkan kwitansi dua rangkap berdasarkan nominal yang ada pada data client, dan diserahkan kepada pimpinan untuk diperiksa dan ditanda tangan. Kwitansi dua rangkap ini akan disimpan satu di pimpinan dan satunya lagi diserahkan ke bagian akuntansi agar bisa diberikan kepada client yang sudah terdaftar, Setiap tanggal 25 client diminta datang ke kantor dengan membawa beberapa berkas dokumen berupa faktur pajak penjualan dan faktur pajak pembelian yang akan diserahkan ke bagian akuntansi agar datanya di input dan dihitung berapa besar yang akan dibayarkan ke negara atau berapa besar lebih bayar, Setelah faktur pajak penjualan dan faktur pajak pembelian diinput dan dihitung yang hasilnya lebih bayar akan keluar data yang disebut SPT PPN DN lebih bayar yang kemudian dicetak dua rangkap yang akan diserahkan kepada client untuk dicap dan ditandatangani, Setelah ditandatangani dokumen SPT PPN DN lebih bayar tersebut akan diserahkan Kembali ke bagian akuntansi berikut uang $f e e$, kemudian bagian akuntansi akan menyerahkan uang fee tersebut kepada pimpinan dan menyimpan pelaporan ke kantor pajak, Setelah selesai menyiapkan pelaporan data SPT PPN DN lebih bayar rangkap pertama akan dilaporkan ke kantor pajak, dan bagian kantor pajak menginput SPT PPN DN lebih bayar akan keluar bukti lapor yang akan diserahkan ke bagian akuntansi untuk diarsipkan, Apabila hasil dari penginputan dan perhitungan dari faktur pajak penjualan dan faktur pajak pembelian kurang bayar akan keluar data yang disebut SPT PPN DN kurang bayar, kemudian bagian akuntansi membuat SSP rangkap tiga dengan senilai yang tercantum pada SPT PPN DN kurang bayar yang akan diberikan kepada client untuk dicap dan ditandatangani, Setelah SPT PPN DN kurang bayar dan SSP rangkap tiga dicap dan ditandatangani akan diserahkan Kembali kebagian akuntansi berikut uang pajak untuk PPN DN dan fee, kemudian uang fee tersebut diserahkan kepada pimpinan dan kebagian akuntansi menyiapkan pembayaran pajak, Setelah selesai menyiapkan pembayaran pajak, SSP rangkap tiga dan uang pajak dibawa kebank untuk dibayar kebank, lalu pihak bank menginput dan keluar bukti bayar yang kemudian diserahkan kepada bagian akuntansi berikut dengan SSP rangkap satu dan dua, sedangkan rangkap tiga diarsipkan oleh pihak bank, Setelah proses pembayaran selesai, bagian akuntansi menyiapkan pelaporan SPT PPN DN dan SSP rangkap satu diarsipkan sedangkan SPT PPN DN kurang bayar dan SSP rangkap dua dibawa ke kantor pajak. Pihak kantor pajak menginput SPT PPN DN dan SSP tersebut lalu keluar dokumen yang disebut bukti lapor yang akan diserahkan ke bagian akuntansi dan bukti lapor tersebut diarsipkan, Dari data client dan kwitansi pada bagian akuntansi akan membuat daftar piutang client yang kemudian diserahkan kepada pimpinan untuk diperiksa. Daftar piutang tersebut dibuat dua rangkap, rangkap kesatu akan disimpan oleh pimpinan sedangkan rangkap yang kedua akan diarsipkan oleh bagian akuntansi

\section{III.3 Use case Diagram}

Berikut merupakan diagram use case Perangkat Lunak Jasa Konsultan Pajak Berbasis Web di Bagian Akuntansi Pada Pt. Stilus Utama Materials Bandung yang diusulkan 


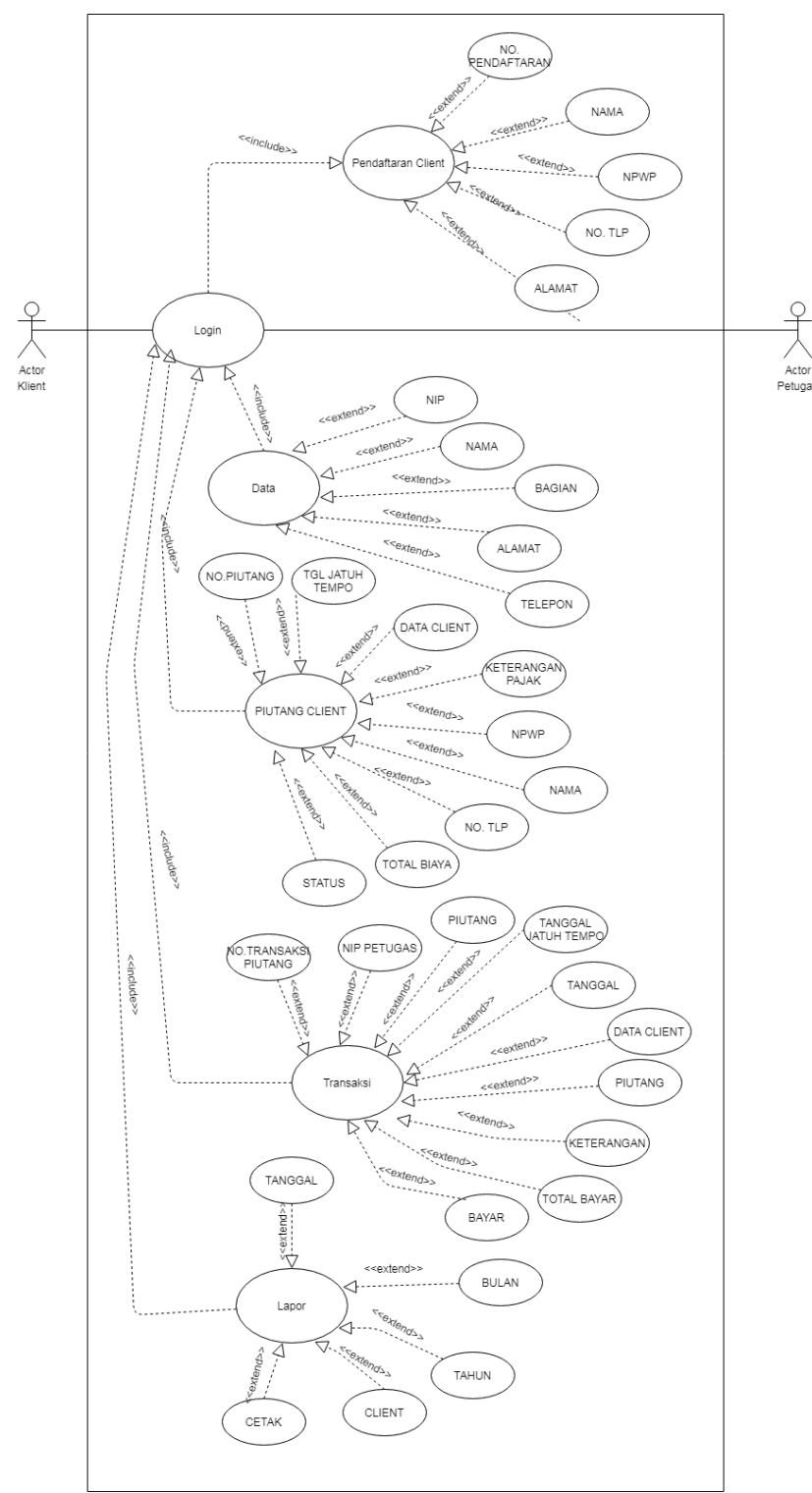

Gambar 1 Usecase Diagram

Pada use case diagram diatas menjelaskan tentang bagaimana seluruh proses yang ada pada sistem.

\section{III.4 Diagram Aktivitas}

Diagram aktivitas buat akun memperlihatkan form buat pendaftaran klien. Actor yang berperan dalam sistem ini adalah client dan petugas. Adapun activity diagram pendaftaran client adalah sebagai berikut

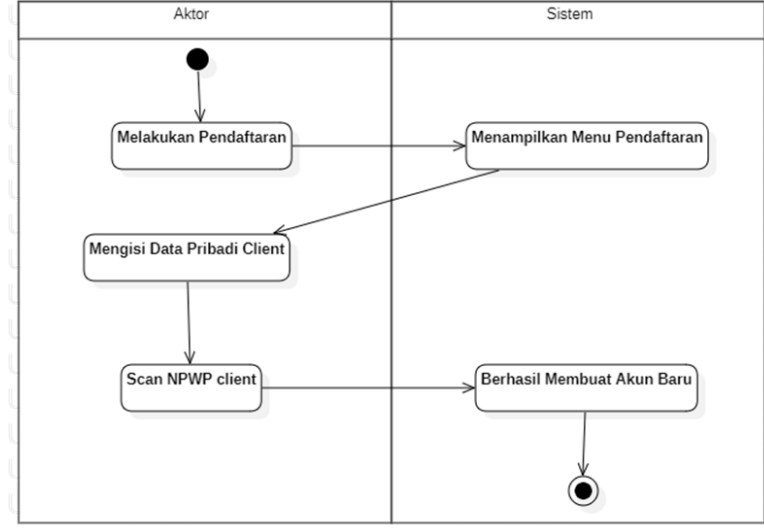

Gambar 2 Activity Diagram Pendaftaran Client

Pada diagram activity di atas menjelaskan tentang bagaimana proses client mendaftar untuk membuat akun pendaftaran client, urutannya yaitu, client dan petugas dapat menampilkan data client, data-data pada use case diatas adalah untuk melihat data-data client yang sudah membuat akun baru, sistem ini dapat melihat dan mengubah data apabila ada kesalahan dalam penginputan pada saat pendaftaran, apabila data-data sudah lengkap maka dapat tersimpan di sistem.

Diagram aktivitas piutang klien dapat memperlihatkan data piutang klien, actor yang berperan dalam sistem ini adalah klien dan petugas. berikut adalah diagram aktivitas piutang klien

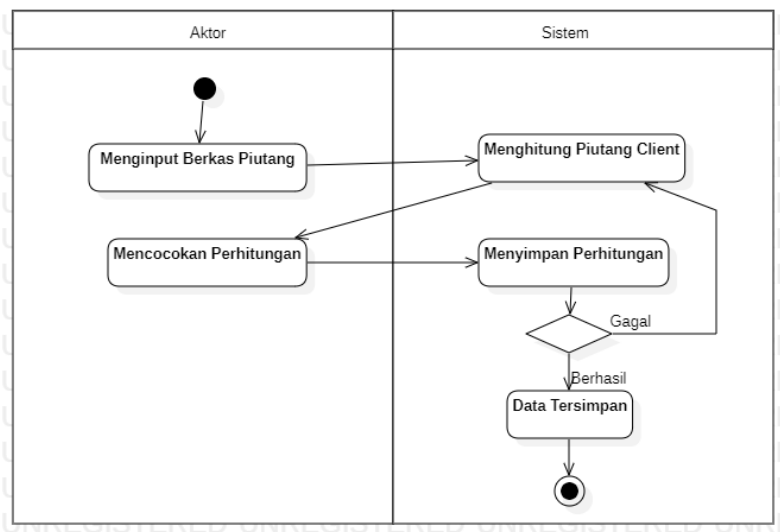

\section{Gambar 3 Activity Diagram Piutang Client}

Pada diagram aktivitas di atas menjelaskan tentang bagaimana proses client mendaftar untuk membuat akun pendaftaran client. Apabila klien mempunyai piutang, maka dapat melakukan penginputan piutang, kemudian menghitung berapa

Heri Purwanto, Mochamad Cory Sakti Triwangsa, Chika Gustiana Widiarestuwati 
jumlah piutang client, setelah perhitungan selesai, data tersimpan.

Diagram aktivitas transaksi dapat memperlihatkan transaksi yang dilakukan klien, adapun diagram aktivitas digambarkan sebagai berikut

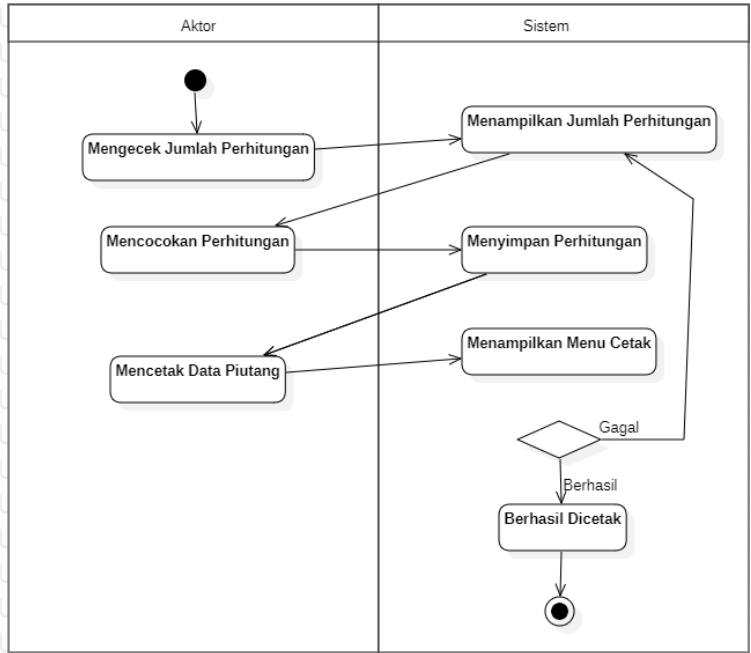

Gambar 4 Activity Diagram Transaksi

Pada aktivitas diagram di atas, pertama klien harus telah melakukan penginputan perhitungan piutang klien, kemudian klien dan petugas mengecek jumlah perhitungan apakah sesuai dengan yang ada pada website pajak, sistem menampilkan seluruh jumlah perhitungan klien, klien dan petugas mencocokan data perhitungan, sistem kemudian menyimpan data perhitungan, klien dan petugas dapat mencetak data perhitungan piutang, kemudian sistem pun dapat menampilkan menu cetak.

Diagram aktivitas lapor pajak dapat memperlihatkan bagaimana proses klien mendaftar untuk membuat akun pendaftaran klien. adapun diagram aktivitas digambarkan sebagai berikut

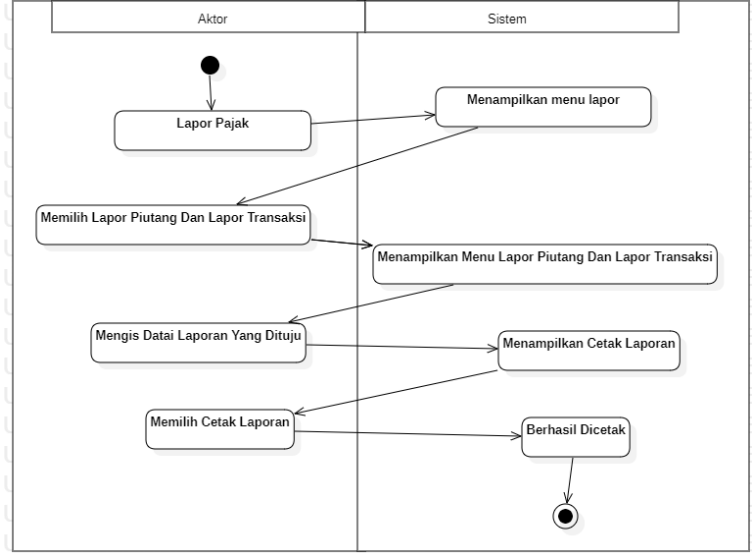

Gambar 5 Activity Diagram Lapor Pajak

Penjelasan alur dari diagram aktivitas yaitu klien dan petugas bisa langsung lapor pajak setelah melakukan semua penginputan di sistem-sistem sebelumnya, sistem akan menampilkan menu lapor pajak, kemudian memilih lapor piutang dan lapor transaksi, sistem lalu menampilkan menu tersebut, klien dan petugas dapat melaporkan pajak, kemudian sistem akan menampilkan menu cetak laporan, jika klien dan petugas memilih menu cetak, maka sistem akan mencetak laporan

\section{III.5 Rancangan Database}

Rancangan Database memperlihatkan seluruh sistem yang ada pada aplikasi. Sebelum membuat rancangan database, class diagram dibuat terlebih dahulu sebagai pedoman dalam pembuatan database. Adapun class diagramnya sebagai berikut.

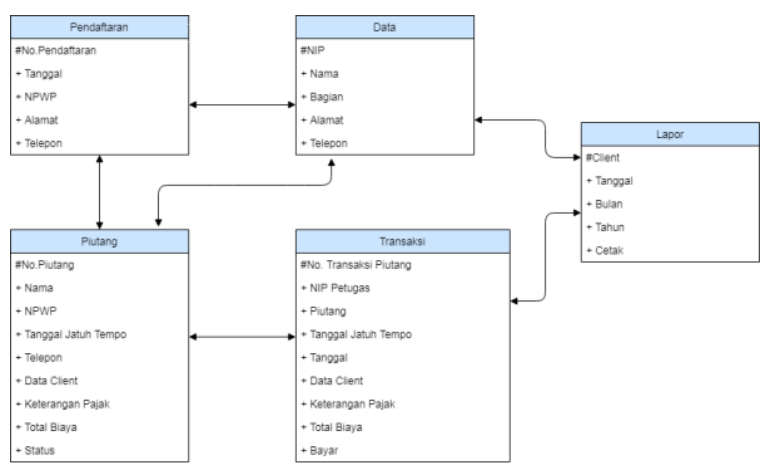

Gambar 6 Diagram Kelas

Pada diagram kelas di atas terdapat tabel pendaftaran terdiri dari no pendaftaran, tanggal, NPWP, alamat, telepon. Yang digunakan untuk menginput data klien pada saat melakukan pendaftaran akun baru, pada tabel data terdiri dari nip,

Heri Purwanto, Mochamad Cory Sakti Triwangsa, Chika Gustiana Widiarestuwati 
nama, bagian, alamat, telepon. Yang digunakan untuk melihat data petugas pada saat klien melakukan penginputan pendaftaran klien baru, pada tabel piutang terdiri dari no piutang, nama, NPWP, tanggal jatuh tempo, telepon, data klien, keterangan pajak, total biaya, status.

Setelah dirancang diagram kelas, maka didapat perancangan database

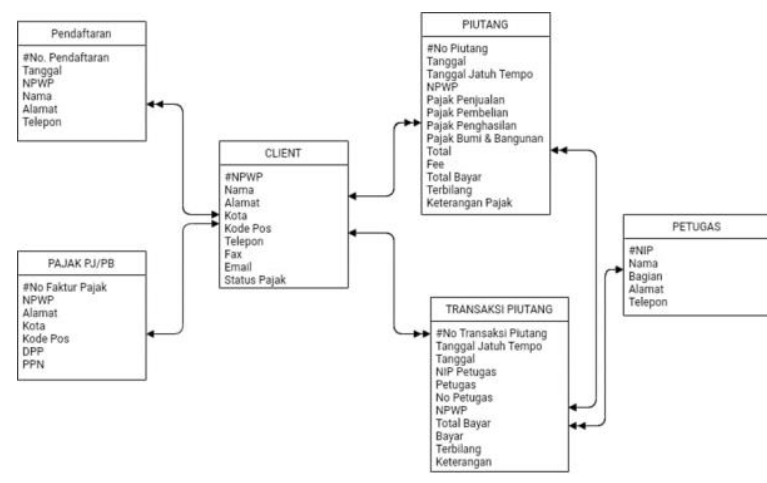

Gambar 7 Perancangan Database

Gambar 7 menggambarkan rancangan database yang akan dibuat, terdapat 6 tabel yang saling berelasi, ada relasi one-to-one, one-to-many, hubungan relasi ini digambarkan menggunakan primary key dan foreign key. Meskipun tidak masuk dalam gambar, terdapat rincian tipe data yang digunakan seperti tanggal menggunakan tipe data date, nama menggunakan tipe data varchar, tipe data total menggunakan tipe data double. Selain jenis tipe data juga dibuat pedoman berapa panjang tipe data tiap tiap varchar yang berfungsi untuk meringankan beban komputer yang akan digunakan, dengan asumsi bahwa data yang masuk kedalam database berjumlah banyak.

Kemudian, setelah dianalisis dan dimodelkan dalam perancangan database, dilakukan perancangan mockup sebagai pedoman dari pembuatan UI aplikasi

\section{III.6 Rancangan Mockup}

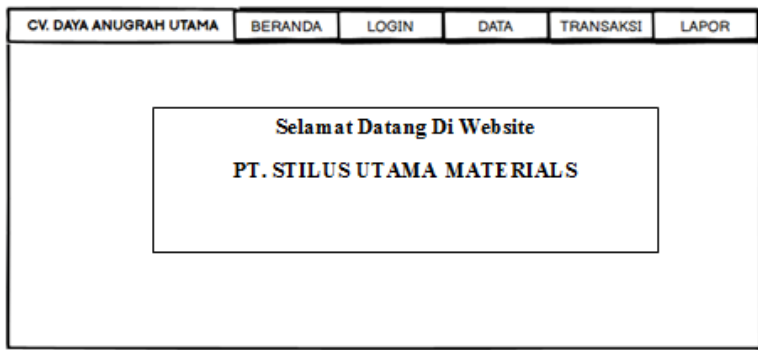

Gambar 8 Rancangan mockup

Gambar 8 menggambarkan mockup dari layout screen pada menu utama aplikasi, menu utama memiliki navbar login, navbar login ini berfungsi untuk memverifikasi apakah user memiliki akses ke dalam sistem, jika user dapat memberi bukti dan telah melakukan login, maka program akan memberikan akses prosedur prosedur yang telah dijelaskan pada Use case sebelumnya.

Semua prosedur yang telah digambarkan dalam use case akan menjadi menu yang dibuat desain mockupnya. Seperti prosedur pendataan client, pendataan piutang, pendataan petugas, dan pendataan transaksi.

Setelah mockup selesai dibuat maka selanjutnya program akan dibuat menggunakan basis web dengan menggunakan framework laravel sebagaimana telah dijelaskan dalam hipotesis.

\section{III.7 Prototype Aplikasi}

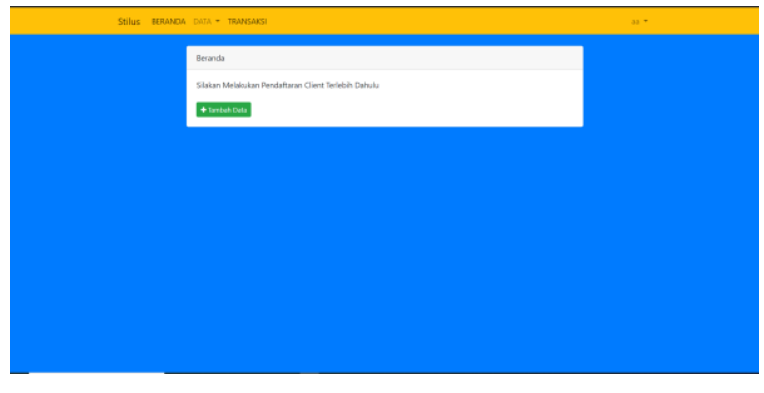

Gambar 9 Menu Utama

Gambar di atas menunjukkan prototype yang telah dibuat. Program telah dibuat berbasis web dengan framework laravel, program dibuat berdasarkan pedoman dan aturan yang telah ditetapkan sebelumnya. 
Di dalam menu utama, admin diwajibkan untuk mengisi data klien terlebih dahulu. Berikut adalah form pengisian data klien

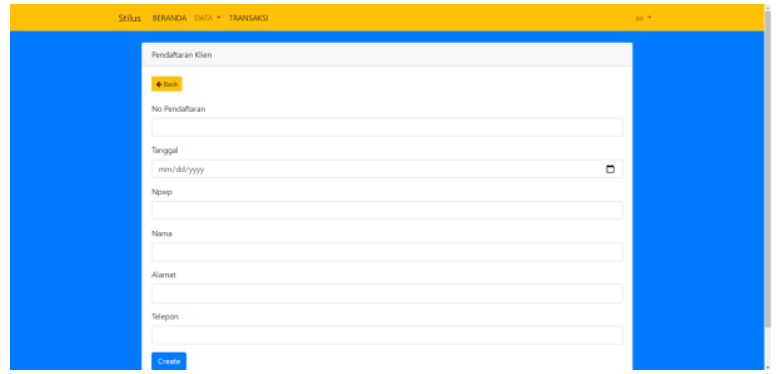

\section{Gambar 10 Form Pendaftaran Klien}

Untuk mengisi form pendaftaran, admin diharapkan meminta NPWP, nama, alamat, telepon klien kepada klien.

Kemudian admin diwajibkan mengisi data diri petugas PT. Stilus Utama Materials. Berikut adalah form pengisian data petugas.

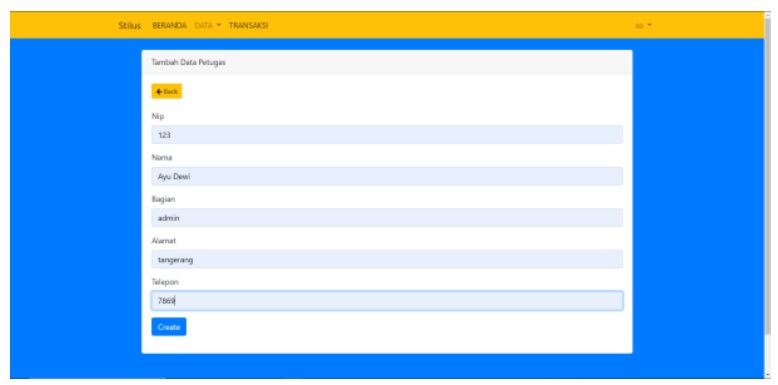

Gambar 11 Form Pendaftaran Petugas

Form pendaftaran petugas diisi sesuai dengan form yang ada di aplikasi dengan data karyawan yang ada di PT. Stilus Utama Materials.

Setelah membuat prototype aplikasi kemudian dilakukan testing untuk memastikan bahwa aplikasi telah berjalan dengan semestinya. komputer yang digunakan untuk testing berada pada tabel di bawah.

Tabel 1. Detail Komputer Testing

\begin{tabular}{ll}
\hline \hline Komponen & Nama Komponen \\
\hline \hline Processor & AMD A8-6410 APU with AMD Radeon R5 \\
& $@ 2,00 \mathrm{GHz}$ \\
VGA & Radeon HD8500M Dual Graphics \\
HDD & $500 \mathrm{~GB}$ \\
RAM & $4 \mathrm{~GB}$ \\
Peripheral & Mouse \& Keyboard \\
OS & Windows 7 \\
\hline \hline
\end{tabular}

Program prototype pun dapat berjalan pada spesifikasi hardware tabel 1

\section{III.8 Melakukan Pengujian}

Perangkat lunak akan diuji menggunakan metode blackbox, metode pengujian ini akan membandingkan hasil yang diharapkan dengan hasil yang ditampilkan dari eksekusi program. Tabel 1 Menyajikan hasil dari pengujian BlackBox Testing

Tabel 2. Pengujian BlackBox Testing

\begin{tabular}{|c|c|c|c|}
\hline $\begin{array}{l}\text { Kelas } \\
\text { Uji }\end{array}$ & Kondisi & Hasil & $\begin{array}{l}\text { Keter } \\
\text { angan }\end{array}$ \\
\hline Login & $\begin{array}{l}\text { Input username dan } \\
\text { password yang } \\
\text { sesuai }\end{array}$ & $\begin{array}{l}\text { Pengguna dapat } \\
\text { masuk ke halaman } \\
\text { utama aplikasi }\end{array}$ & Valid \\
\hline Login & $\begin{array}{l}\text { Input username dan } \\
\text { password yang salah }\end{array}$ & $\begin{array}{l}\text { Tidak bisa login } \\
\text { akan muncul eror }\end{array}$ & Valid \\
\hline Data & $\begin{array}{l}\text { Input nama, } \\
\text { keterangan, status, } \\
\text { waktu berakhir } \\
\text { proyek yang sesuai }\end{array}$ & $\begin{array}{l}\text { Akan menampilkan } \\
\text { data yang sesuai }\end{array}$ & Valid \\
\hline Data & $\begin{array}{l}\text { Input nama, } \\
\text { keterangan, status, } \\
\text { waktu berakhir } \\
\text { proyek yang sesuai }\end{array}$ & $\begin{array}{l}\text { Apabila data tidak } \\
\text { sesuai akan error }\end{array}$ & Valid \\
\hline $\begin{array}{l}\text { Transa } \\
\text { ksi }\end{array}$ & $\begin{array}{l}\text { Input nama, } \\
\text { keterangan, status, } \\
\text { waktu berakhir } \\
\text { proyek yang sesuai }\end{array}$ & $\begin{array}{l}\text { Akan menampilkan } \\
\text { data benar,maka } \\
\text { akan cetak bukti } \\
\text { bayar }\end{array}$ & Valid \\
\hline $\begin{array}{l}\text { Transa } \\
\text { ksi }\end{array}$ & $\begin{array}{l}\text { Input nama, } \\
\text { keterangan, status, } \\
\text { waktu berakhir } \\
\text { proyek yang sesuai }\end{array}$ & $\begin{array}{lr}\text { Tidak } & \text { akan } \\
\text { menampilkan data } \\
\text { benar,maka akan } \\
\text { cetak bukti bayar } \\
\text { dan akan muncul } \\
\text { eror }\end{array}$ & Valid \\
\hline Lapor & $\begin{array}{l}\text { Input } \\
\text { tanggal,bulan,tahun } \\
\text { dan kriteria }\end{array}$ & $\begin{array}{l}\text { Akan menampilkan } \\
\text { data lapor pajak }\end{array}$ & Valid \\
\hline Lapor & $\begin{array}{l}\text { Input } \\
\text { tanggal,bulan,tahun } \\
\text { dan kriteria yang } \\
\text { salah }\end{array}$ & $\begin{array}{lr}\text { Tidak } & \text { Akan } \\
\text { menampilkan } & \text { data } \\
\text { lapor pajak } & \end{array}$ & Valid \\
\hline
\end{tabular}

\section{KESIMPULAN DAN SARAN}

Berdasarkan pengujian, Prototype aplikasi dapat bekerja dan memenuhi proses bisnis berjalan pada perusahaan PT. STILUS UTAMA MATERIALS serta dapat memberikan informasi tentang piutang klien dengan tepat dan meminimalisir penumpukan dan kehilangan data klien.

Penelitian selanjutnya akan dicoba menggunakan basis lain seperti node js. Berbeda dengan laravel

Heri Purwanto, Mochamad Cory Sakti Triwangsa, Chika Gustiana Widiarestuwati 
yang menggunakan php sebagai basis pemrogramannya, node js menggunakan basis javascript. Atau aplikasi dikembangkan dalam bentuk mobile apps.

\section{REFERENSI}

Ariesandika, D., Wicaksono, S. A., \& Pradana, F. (2018). Pengembangan Sistem Informasi Monitoring Pekerjaan Kantor Konsultan Pajak Berbasis Web pada Kantor Konsultan Pajak I Gede Arianta. Jurnal Pengembangan Teknologi Informasi dan Ilmu Komputer (J-PTIIK) Universitas Brawijaya, 2(11), 5807-5815. Retrieved from http://jptiik.ub.ac.id/index.php/jptiik/article/view/3434

Dalimunthe, A. H. (2016). Desain Basis Data Sistem Pemesanan Makanan dan Minuman Pada Restoran Berbasis Online. Jurnal Rekayasa Elektro Sriwijaya, 1(2), 53-61.

E. Lewis, W. (2016). Software Testing and Continous Quality Improvement 3rd Edition. U.S.A: Taylor \& Francis Group.

Ediraras, D. (2010). Akuntansi Dan Kinerja Ukm. Jurnal Ilmiah Ekonomi Bisnis, 15(2), 5936.

Fitriani, A., \& Sulistyawati, A. I. (2020). Faktor Faktor Yang Mempengaruhi Terjadinya Tax Avoidance Pada Perusahaan Manufaktur Yang Terdaftar Di Bursa Efek Indonesia. E-Jurnal Akuntansi Universitas Udayana, 18(2), 143161.

Fridayanthie, Wida, E., \& Mahdiati, T. (2016). Rancang Bangun Sistem Informasi Permintaan Atk Berbasis Intranet. Khatulistiwa Informatika, 4(2), 126-138.

Handayani, S. (2018). Perancangan Sistem Informasi Penjualan Berbasis E-Commerce Studi KaHandayani, S. (2018). Perancangan Sistem Informasi Penjualan Berbasis E-Commerce Studi Kasus Toko Kun Jakarta. ILKOM Jurnal Ilmiah, $\quad 10(2), \quad 182-189$. https://doi.org/10.33096/ilkom.v10i2.310. ILKOM Jurnal Ilmiah, 10(2), 182-189.

Hardiningsih, P. (2011). Faktor-Faktor Yang Mempengaruhi Kemauan Membayar Pajak (The Factors That Influence The Willingness To Pay The Tax). Dinamika Keuangan Dan Perbankan,
3(1), 126-143.

Khairiyah, Y. R., \& Akhmadi, M. H. (2018). Analisis Perpajakan Terhadap Bentuk Usaha Tetap Berbasis Layanan Aplikasi. Jurnal Kementrian Keuangan, 1, 125-130.

Lutfi, A. (2017). Sistem Informasi Berbasis WEB Pada Kedai Kopi ABG, 2(3), 366-371.

Mandak, A., \& Morasa, J. (2015). Prosedur Perhitungan Dan Pelaporan Pajak Penghasilan Pasal 21 Atas Gaji Pegawai Pemerintah Kabupaten Minahasa Selatan. Jurnal Riset Akuntansi, 283.

Maulana, Y. I. (2017). Perancangan Perangkat Lunak Sistem Informasi Pendataan Guru Dan Sekolah (SINDARU) Pada Dinas Pendidikan Kota Tangerang Selatan. Jurnal Pilar Nusa Mandiri, 13(1), 21-27.

Mulyani, A. S., Nurhayaty, E., \& Miharja, K. (2019). Penerapan Pencatatan dan Laporan Akuntansi Pada Usaha Mikro Kecil Dan Menengah (UMKM). Jurnal Abdimas BSI: Jurnal Pengabdian Kepada Masyarakat, 2(2), 219226.

Mumtahana, H. A., Nita, S., \& Tito, A. W. (2017). Pemanfaatan Web E-Commerce untuk Meningkatkan Strategi Pemasaran. Khazanah Informatika: Jurnal Ilmu Komputer dan Informatika, 3(1), 6.

Prasetyo, E. (2020). Aplikasi Pencatatan Cuti Pegawai Negeri Sipil pada Badan Kepegawaian dan Pengembangan Sumber Daya Manusia Kabupaten Musi Banyuasin. Jurnal TIPS: Jurnal Teknologi Informasi dan Komputer Politeknik Sekayu, 10(1), 7-12. Retrieved from http://dx.doi.org/10.1016/j.biochi.2015.03.025\% $0 \mathrm{~A}$

Primawati, A., \& Mustari, D. (2014). Analisis Manajemen Proyek Perangkat Lunak Sistem Informasi Akuntansi Pada Biro Sistem Informasi Pt. X. Jurnal Sistem Informasi, 9(2), 101.

Suhartanto, M. (2016). Pembuatan Website Sekolah Menengah Pertama Negeri 3 Delanggu Dengan Menggunakan Php Dan Mysql. Sentra Penelitian Engineering dan Edukasi, 4(1), 1-8. Retrieved from http://speed.web.id/ejournal/index.php/Speed/ar ticle/view/226

Heri Purwanto, Mochamad Cory Sakti Triwangsa, Chika Gustiana Widiarestuwati 
Tegar. (2014). Evaluasi Terhadap Sistem Pencatatan Akuntansi Pada Usaha Mikro, Kecil Dan Menengah.

Urva, G., Siregar, H. F., Prof, J., Kisaran, M. Y., \& Utara, S. (2015). Pemodelan UML EMarketing Minyak Goreng. Open Access Journal Of Information System, 2(9), 92-101.

Wibisono, A. Y., Surya, D., Putra, D., \& Margita, S. (2020). Aplikasi Gaji Karyawan dan Perhitungan Pajak Penghasilan Pasal 21 Berbasis Website dengan menggunakan Framework CodeIgniter. Jurnal ALGOR, 1 . 